\title{
Effects of Self-Enhancement on Eye Movements During Reading
}

\author{
Ya Lou ${ }^{1,2,3}$, Huajian Cai ${ }^{1,2}$, Xuewei Liu' ${ }^{1,2}$ and Xingshan Li $^{1,2 *}$ \\ ${ }^{1}$ CAS Key Laboratory of Behavioral Science, Institute of Psychology, Beijing, China, ${ }^{2}$ Department of Psychology, University \\ of Chinese Academy of Sciences, Beijing, China, ${ }^{3}$ Beijing Institute of Education, Beijing, China
}

Previous studies show that readers' eye movements are influenced by text properties and readers' personal cognitive characteristics. In the current study, we further show that readers' eye movements are influenced by a social motivation of self-enhancement. We asked participants to silently read sentences that describe self or others with positive or negative traits while their eyes were monitored. First-fixation duration and gaze duration were longer when positive words were used to describe self than to describe others, but there was no such effect for negative words. These results suggest that eye movements can be influenced by the motivation of self-enhancement in addition

OPEN ACCESS

Edited by:

Andriy Myachykov,

Northumbria University,

United Kingdom

Reviewed by:

Stefan Hawelka,

University of Salzburg, Austria Kevin B. Paterson,

University of Leicester,

United Kingdom

*Correspondence:

Xingshan L

lixs@psych.ac.cn

Specialty section:

This article was submitted to

Language Sciences,

a section of the journal

Frontiers in Psychology

Received: 01 November 2018

Accepted: 04 February 2019

Published: 25 February 2019

Citation:

Lou Y, Cai H, Liu X and Li X (2019) Effects of Self-Enhancement on Eye

Movements During Reading.

Front. Psychol. 10:343.

doi: 10.3389/fpsyg.2019.00343 to various stimuli features and cognitive factors. This finding indicates that the eye movement methodology can potentially be used to study implicit social cognition.

Keywords: self enhancement, reading, eye movements, language sciences, personality and social psychology

\section{INTRODUCTION}

We move our eyes three to four times per second when we are awake to selectively perceive visual information that is most salient or most relevant to our current task (Rayner, 1998, 2009). Decades of eye movement research has shown that our eye movements are influenced by various features of visual stimuli (e.g., words frequency in reading) (Rayner, 1998, 2009) and diverse personal cognitive characteristics (e.g., reading skills) (Rayner and Reichle, 2010; Kuperman and Dyke, 2011). For example, high-frequency words are typically fixated for less time and skipped more often than low-frequency words (Inhoff and Rayner, 1986; Rayner and Duffy, 1986); skilled readers make shorter fixations on words, longer forward saccades (Jared et al., 1999; Ashby et al., 2005), and fewer regressions compared to less-skilled readers (Ashby et al., 2005). Moreover, the eye movements also vary with purposes. For example, Kaakinen et al. (2002) examined the effects of reading goals on eye movement behavior. The reading goal was induced by instructing the participants to imagine that they were going to live in another country. Then the participants were asked to read an expository text that included four remote countries. They found that readers made more and longer fixations on sentences that described the conditions of that country than on other sentences. The current research aims to explore whether eye movement in reading could be influenced by a special human motivation, that is, the desire for a positive self or self-enhancement.

Word processing time might also be affected by high-level cognition such as motivation. For example, self-enhancement, a type of motivation that works to make people feel good about themselves, might affect eye movements during reading. Self-enhancement makes people favor positive over negative self-views (Sedikides and Gregg, 2008). A positive self is significant for 
physical and mental health (Taylor and Brown, 1988), wellbeing (Baumeister et al., 2003), and coping with threats and life difficulties (see Alicke and Sedikides, 2009 for a review). Self-positivity may manifest on various behavioral indexes, such as trait endorsement (D’Argembeau et al., 2005; Kwan et al., 2007), reaction time (Paulhus and Levitt, 1987; Gebauer et al., 2012), and neural responses, such as electroencephalograph (EEG) signal (Luck, 2005; Cai et al., 2016; Hampton and Varnum, 2017). Therefore, self-enhancement might influence people's attention allocation during reading, favoring positive information about self.

This research explored whether self-enhancement manifests in eye movements in reading, or whether self-enhancement influences eye movements in reading self-relevant information. Accordingly, the participants were asked to silently read sentences that describe the self or others with positive or negative traits while their eyes were monitored. Each sentence contained one identity word (i.e., I or $\mathrm{He}$ ) and one attribute word (i.e., positive or negative) (see Figure 1 for examples). Previous studies showed that people tend to judge positive personality attributes to be more appropriate in describing themselves than in describing others and therefore self-enhancement may encourage people to "elaborate, dwell on" positive self-evaluative information (Heine et al., 1999, p. 760). We inferred that positive traits that describe the self may obtain longer fixation time than those describing the other person (i.e., he).

\section{MATERIALS AND METHODS}

\section{Participants}

A total of 40 undergraduate students from Beijing Forestry University and China Agricultural University participated in this experiment. Three participants were excluded because of technical problems or track loss during eye movement recording. Participants provided consent in accordance with the protocols approved by the ethics committee of Institute of Psychology, Chinese Academy of Sciences.

\section{Apparatus}

Eye movements were recorded using an SR-Research Eyelink 1000 eye tracker (Kanata, ON, Canada) sampling at a rate of $1,000 \mathrm{~Hz}$. Eye movements were recorded from the right eye during binocular viewing. The sentences were displayed as a single line of text using 24 point Song font. The participants were seated at a distance of $58 \mathrm{~cm}$ from the computer monitor.

\section{Materials and Design}

The trait words were adapted from a previous study (Cai, 2003), and comprised 12 positive words and 12 negative words (see Table 1). The average frequency of the positive trait words $(M=45.53$ occurrences per million words, $S D=56.69)$ was higher than that of the negative ones $(M=8.59$ occurrences per million words, $S D=10.95)$. Each trait word was embedded in two different sentence frames with the following subjects in the sentences: one with the embedded word "I" preceding the trait word and the other with "He." The word "I" and "He" were used as identity words. Therefore, 12 sentences were created for each of the following four conditions: I-positive, He-positive, Inegative, and He-negative (see Figure 1). The average sentence length ranged from 16 to 30 characters with a mean of 20.85 characters and a standard deviation of 3.45. The same number of sentences was created as filler sentences in which neither identity nor trait word was included.

\section{Procedure}

The participants were tested individually. When they arrived at the lab, they were informed that this experiment was designed to use an eye tracking technology to investigate sentencecomprehension processes. However, they were unaware of the experiment's purpose. Thereafter, they performed a calibration procedure by looking at a sequence of three fixation points that were randomly displayed horizontally across the middle of the computer screen. The maximal calibration error was $0.5^{\circ}$. Calibration was conducted at the beginning of the experiment and was conducted again during the experiment when necessary. At the beginning of each trial, a drift check was conducted to ensure that the error of the eye tracker was within the allowable range. Thereafter, the participants looked at a square located at the position of the first character of the sentence. After they fixated at this square for $0.5 \mathrm{~s}$, the entire sentences appeared. The participants silently read the sentences, and they were required to press a button when they had completed reading these sentences. A comprehension question with a two-alternative forced-choice response was asked after each of all the 24 filler items and participants responded by pressing one of two keys on a response box. These questions were created to ensure that the participants carefully read the sentences. The mean accuracy of the comprehension questions was 95\%, thereby indicating that the participants carefully read the sentences.

\section{Data Analysis}

Fixations above $1000 \mathrm{~ms}$ or below $80 \mathrm{~ms}$ were excluded from analyses. We report the following eye movement measures for the target words in the sentences (Rayner, 1998): (a) First-fixation duration (duration of the first first-pass fixation on the target word), (b) Gaze duration (sum of all first-pass fixations on the target word prior to proceeding to another word), (c) Skipping probability (the probability that the target word was skipped on first-pass reading), and (d) Total reading time (sum of all fixations on the target word, including regression). First-fixation duration and gaze duration are sensitive to early processing associated with lexical identification, whereas total reading times are sensitive to later processes associated with integration (Inhoff, 1984). Table 2 presents the descriptive statistics of these eye movement measures.

Given that high-frequency words are processed faster than low-frequency words (known as frequency effect) (Rayner and Duffy, 1986), and the frequency of the positive trait words were higher than those of the negative trait words, and the comparison between negative and positive words was not relevant to our research question, we did not directly compare eye movement measures between the negative words and positive words. 


\section{Materials used in the experiment.}

\section{I-positive Condition}

我幼时我巧伶俐，从三岁起就随父亲练字。

I had been a clever child; I studied calligraphy with my farther starting at three-years old.

\section{He-positive Condition}

他口齿伶俐, 每次发言都滔滔不绝。

$\underline{\mathrm{He}}$ is an articulate man and not afraid to speak his mind.

I-negative Condition

我在跳舞时动作笨拙, 蹒跚摇晃, 险些儿跌跤。

I felt awkward when I was dancing, I staggered and swayed and nearly fell down.

He-negative Condition

他口才笨拙, 不流利的发言一度成为全校笑柄。

His unprofitable eloquence at schoolwide banquets has been the butt of many jokes

FIGURE 1 | Materials used in experiment. The identify words are underlined and the trait words are in bold letters for the purpose of illustration (the characters were neither underlined nor made bold in the experiment).

TABLE 1 | Trait words used in this experiment.

\begin{tabular}{|c|c|c|c|c|c|c|}
\hline \multicolumn{7}{|c|}{ Trait words } \\
\hline Negative & $\begin{array}{l}\text { 愚蚌 } \\
\text { (stupid) } \\
\text { 罪恶 } \\
\text { (evil) }\end{array}$ & $\begin{array}{l}\text { 丑陃 } \\
\text { (ugly) } \\
\text { 笨拙 } \\
\text { (stupid) }\end{array}$ & $\begin{array}{l}\text { 失败 } \\
\text { (unsuccessful) } \\
\text { 堕落 } \\
\text { (corrupt) }\end{array}$ & $\begin{array}{l}\text { 讨厌 } \\
\text { (disgusting) } \\
\text { 可恨 } \\
\text { (hateful) }\end{array}$ & $\begin{array}{c}\text { 无能 } \\
\text { (incapable) } \\
\text { 虚弱 } \\
\text { (feebleness) }\end{array}$ & $\begin{array}{l}\text { 卑鄙 } \\
\text { (contemptible) } \\
\text { 可耻 } \\
\text { (disgraceful) }\end{array}$ \\
\hline
\end{tabular}

Instead, the key comparisons were the results between the $I-$ positive and He-positive conditions and between the I-negative and He-negative conditions.

Eye movement data were analyzed using linear mixedeffects models (LMM) for continuous variables (Baayen et al., 2008; Jaeger, 2008), in which the participants and items were considered as random effects. Identity words, trait words, and their interactions were entered as fixated effects. The analyses were performed using the lme4 package (Bates et al., 2014) in the R statistical software (Version 3.3.1, R Core Team, 2016), and the lmerTest Package was used to get the $p$-value for tests for fixed effects.

\section{RESULTS}

\section{First-Fixation Duration}

First-fixation durations were shorter in the positive condition $(M=223 \mathrm{~ms}, S E=4)$ than in the negative condition
$(M=229 \mathrm{~ms}, \quad S E=4), \quad b=-22.575, \quad S E=10.279$, $t=-2.196, p=0.03$. No difference was observed between the identity conditions (the $I$ condition: $M=228 \mathrm{~ms}, S E=4$, the $H e$ condition: $M=224 \mathrm{~ms}, S E=4), t=-1.410$, $p=0.158$. However, the interaction effect between the trait

TABLE 2 | Eye movement measures in the trait word region.

\begin{tabular}{|c|c|c|c|c|c|c|c|c|}
\hline \multirow[b]{3}{*}{ First-fixation duration } & \multicolumn{4}{|c|}{ Positive } & \multicolumn{4}{|c|}{ Negative } \\
\hline & \multicolumn{2}{|c|}{ I } & \multicolumn{2}{|c|}{ HE } & \multicolumn{2}{|c|}{ I } & \multicolumn{2}{|c|}{ HE } \\
\hline & 231 & (5) & 214 & (5) & 226 & (5) & 233 & (6) \\
\hline Skipping probability & 0.28 & $(0.02)$ & 0.33 & $(0.02)$ & 0.23 & $(0.02)$ & 0.25 & $(0.02)$ \\
\hline Gaze duration & 284 & (12) & 257 & (10) & 259 & (8) & 261 & (8) \\
\hline Total reading time & 368 & (15) & 373 & (15) & 332 & (12) & 334 & (12) \\
\hline Regression in & 0.12 & $(0.02)$ & 0.12 & $(0.02)$ & 0.10 & $(0.01)$ & 0.10 & $(0.01)$ \\
\hline
\end{tabular}

First-fixation duration, gaze duration, and total time were measured in $\mathrm{ms}$. SEs are provided in parentheses. 
valence and identity was significant, $b=28.591, S E=10.516$, $t=2.719, p<0.01$.

Planned comparisons showed that first-fixation durations in the He-positive condition $(M=214 \mathrm{~ms}, S E=5)$ were shorter than those in the I-positive condition $(M=231 \mathrm{~ms}, S E=5)$, $b=17.795, S E=7.136, t=2.494, p=0.01$. First-fixation duration on the negative trait words did not differ between the $\mathrm{He}$ negative condition $(M=233 \mathrm{~ms}, S E=6)$ and I-negative condition $(M=231 \mathrm{~ms}, S E=5), t=-1.2, p=0.2$.

\section{Gaze Duration}

The interaction effect of the trait words and identity was not significant, $b=34.407, S E=18.207, t=1.890, p=0.06$. No main effect of the trait word and identity was observed, both $t<1$. Since the interaction was close to significant, we also conducted some further exploratory analyses. Planned comparisons showed that gaze durations were shorter in the $\mathrm{He}$-positive $(M=258 \mathrm{~ms}$, $S E=10)$ than those in the I-positive $(M=284 \mathrm{~ms}, S E=12)$ condition, $b=27.56, S E=14.31, t=1.93, p=0.05$. Gaze duration on the trait words did not differ between the He-negative $(M=261 \mathrm{~ms}, S E=8)$ and $I$-negative condition $(M=259 \mathrm{~ms}$, $S E=8), t<1$. The pattern of gaze duration replicated the results from the first-fixation duration.

\section{Other Measures}

Neither the main effects of the trait words, identity, nor the interaction were significant for the other measures (skipping probability, total time, all $t<1$ ).

\section{DISCUSSION}

This study analyzed whether human motivation, particularly selfenhancement, influences eye movements during reading. The identity words (i.e., I versus $\mathrm{He}$ ) and trait words (i.e., positive versus negative) were embedded in the sentences. Accordingly, four sentence conditions (i.e., I-positive, $\mathrm{He}$-positive, I-negative, and $\mathrm{He}$-negative) were created. As expected, we found that firstfixation duration and gaze duration in the I-positive condition were longer than those in the He-positive condition. However, we found no difference in fixation time on negative words.

These findings showed that self-enhancement can affect eye movement behavior during reading. To enhance or maintain a positive self, people often selectively remember their strengths rather than weaknesses. One way to do this is at the encoding stage of memory through selective attention. As a result, people dwell longer on positive words that describe self in reading. These results suggest that eye movements are affected by reading-related factors (e.g., reading material features and reading ability) and human motivation (e.g., self-enhancement), thereby extending our understanding of the range of factors that can affect mechanisms of eye movement control during reading.

For negative traits, we did not observe shorter fixation time on negative words that describing $I$ than those that describe $h e$. Two factors might have jointly affected the processing of negative words. First, negative words that describing I might be processed for shorter time than those that describe he due to the need for self-protection. However, there may be considerably longer fixation time because negative self-information may constitute a conflict with the existing self-positivity, thereby attracting further attention due to its inconsistency or novelty. These two opposite factors might have caused a small difference (or no difference) in fixation time between the two negative conditions.

In addition to enhancing our understanding of eye movement control during reading, our findings also suggest that eye movement methodology can be used to study the on-line effects of self-positivity during comprehension. Previous studies have used self-report scales (Rosenberg, 1965), reaction time task (e.g., Implicit Association Test or IAT, Greenwald et al., 1998), and electroencephalograph EEG signal (Luck, 2005; Wu et al., 2016) to measure self-positivity. Compared with other methodologies, eye tracking technique has a few advantages. First, this technique reflects moment-to-moment cognitive processes without interfering with the natural behavior of the participants. Second, eye movement data provide the researcher with valuable temporal information about exactly when a manipulation exerts influences. Moreover, the task is based on spontaneous reactions, thereby possibly assisting in sidestepping many artifacts, such as social desirability and response styles.

There are some limitations in the current study. First, we only used limited number of stimuli. Further studies are needed to investigate whether the effects observed in the current study can be extended to other types of positive and negative words. Second, we did not directly compare the effects that were observed with eye tracking technology with the findings that were observed using other technologies. Further studies are needed to address these issues.

In summary, we showed that eye movements can be influenced by the motivation of self-enhancement beyond various stimuli features and cognitive factors. This finding broadens our understanding of the sensitivity of eye movements to high level cognitive processes by showing that differences in the processing of self versus other descriptive words are detectable in early processing using eye movement measures.

\section{AUTHOR CONTRIBUTIONS}

XiL and YL designed the experiments. YL and XuL carried out experiments and analyzed the experimental results. YL, XiL, XuL, and $\mathrm{HC}$ wrote the manuscript.

\section{FUNDING}

This research was jointly funded by the National Natural Science Foundation of China (NSFC) and the German Research Foundation (DFG) in Project Crossmodal Learning, NSFC 61621136008/DFC TRR-169. This research was supported by a grant from the National Natural Science Foundation of China (31571125) and a grant from the National Social Science Fund of China (17ZDA305). This research was also supported by CAS Key Laboratory of Behavioral Science, Institute of Psychology. 


\section{REFERENCES}

Alicke, M. D., and Sedikides, C. (2009). Self-enhancement and self-protection: what they are and what they do. Eur. Rev. Soc. Psychol. 20, 1-48. doi: 10.1080/ 10463280802613866

Ashby, J., Rayner, K., and Clifton, C. (2005). Eye movements of highly skilled and average readers: differential effects of frequency and predictability. Q. J. Exp. Psychol. A 58, 1065-1086. doi: 10.1080/02724980443000476

Baayen, R. H., Davidson, D. J., and Bates, D. M. (2008). Mixed-effects modeling with crossed random effects for subjects and items. J. Mem. Lang. 59, 390-412. doi: 10.1016/j.jml.2007.12.005

Bates, D., Maechler, M., Bolker, B., and Walker, S. (2014). Ime4: Linear Mixed-Effects Models Using Eigen and S4. R Package Version. Available at: https://www.researchgate.net/publication/279236477_Package_Lme4_Linear_ Mixed-Effects_Models_Using_Eigen_and_S4

Baumeister, R. F., Campbell, J. D., Krueger, J. I., and Vohs, K. D. (2003). Does high self-esteem cause better performance, interpersonal success, happiness, or healthier lifestyles? Psychol. Sci. Public Interest 4, 1-44. doi: 10.1111/1529-1006. 01431

Cai, H. (2003). Nei yin zi zun ji nei yin zi zun yu wai xian zi zun de guan xi [The implicit self-esteem among Chinese in relation to explicit self-esteem]. Acta Psychol. Sin. 35, 796-801.

Cai, H., Wu, L., Shi, Y., Gu, R., and Sedikides, C. (2016). Self-enhancement among Westerners and Easterners: a cultural neuroscience approach. Soc. Cogn. Affect. Neurosci. 11, 1569-1578. doi: 10.1093/scan/nsw072

D’Argembeau, A., Comblain, C., and Van der Linden, M. (2005). Affective valence and the self-reference effect: influence of retrieval conditions. Br. J. Psychol. 96, 457-466. doi: 10.1348/000712605X53218

Gebauer, J. E., Göritz, A. S., Hofmann, W., and Sedikides, C. (2012). Self-love or other-love? Explicit other-preference but implicit self-preference. PloS One 7:e41789. doi: 10.1371/journal.pone.0041789

Greenwald, A. G., McGhee, D. E., and Schwartz, J. L. (1998). Measuring individual differences in implicit cognition: the implicit association test. J. Personal. Soc. Psychol. 74:1464. doi: 10.1037/0022-3514.74.6.1464

Hampton, R. S., and Varnum, M. (2017). Do cultures vary in self-enhancement? ERP, behavioral, and self-report evidence. Soc. Neurosci. 13, 566-578. doi: 10. 1080/17470919.2017.136147

Heine, S. J., Lehman, D. R., Markus, H. R., and Kitayama, S. (1999). Is there a universal need for positive self-regard? Psychol. Rev. 106, 766-794.

Inhoff, A. W. (1984). Two stages of word processing during eye fixations in the reading of prose. J. Verbal Learning Verbal Behav. 23, 612-624. doi: 10.1016/ S0022-5371(84)90382-7

Inhoff, A. W., and Rayner, K. (1986). Parafoveal word processing during eye fixations in reading: effects of word frequency. Percept. Psychophys. 40, 431-439. doi: $10.3758 / \mathrm{BF} 03208203$

Jaeger, T. F. (2008). Categorical data analysis: away from ANOVAs (transformation or not) and towards logit mixed models. J. Mem. Lang. 59, 434-446. doi: 10.1016/j.jml.2007.11.007

Jared, D., Levy, B. A., and Rayner, K. (1999). The role of phonology in the activation of word meanings during reading: evidence from proofreading and eye movements. J. Exp. Psychol. Gen. 128, 219-264. doi: 10.1037/0096-3445.128. 3.219

Kaakinen, J. K., Hyönä, J., and Keenan, J. M. (2002). Perspective effects on online text processing. Dis. Process. 33, 159-173. doi: 10.1207/S15326950DP3302_03

Kuperman, V., and Dyke, J. A. V. (2011). Effects of individual differences in verbal skills on eye-movement patterns during sentence reading. J. Mem. Lang. 65, 42-73. doi: 10.1016/j.jml.2011.03.002

Kwan, V. S., Barrios, V., Ganis, G., Gorman, J., Lange, C., Kumar, M., et al. (2007). Assessing the neural correlates of self-enhancement bias: a transcranial magnetic stimulation study. Exp. Brain Res. 182, 379-385. doi: 10.1007/s00221007-0992-2

Luck, S. J. (2005). An Introduction to the Event-Related Potential Technique. Cambridge, MA: MIT Press.

Paulhus, D. L., and Levitt, K. (1987). Desirable responding triggered by affect: automatic egotism? J. Personal. Soc. Psychol. 52, 245-259. doi: 10.1037/00223514.52.2.245

R Core Team (2016). R: A Language and Environment for Statistical Computing. Vienna, Austria: R Foundation for Statistical Computing. Available at: https: //www.R-project.org/

Rayner, K. (1998). Eye movements in reading and information processing: 20 years of research. Psychol. Bull. 124, 372-422. doi: 10.1037/0033-2909.124.3.372

Rayner, K. (2009). Eye movements and attention in reading, scene perception, and visual search. Q. J. Exp. Psychol. 62, 1457-1506. doi: 10.1080/ 17470210902816461

Rayner, K., and Duffy, S. A. (1986). Lexical complexity and fixation times in reading: effects of word frequency, verb complexity, and lexical ambiguity. Mem. Cogn. 14, 191-201. doi: 10.3758/BF03197692

Rayner, K., and Reichle, E. D. (2010). Models of the reading process. wiley interdisciplinary reviews. Cogn. Sci. 1, 787-799.

Rosenberg, M. (1965). Society and the Adolescent Self-Image. Princeton, NJ: Princeton university press. doi: 10.1515/9781400876136

Sedikides, C., and Gregg, A. P. (2008). Self-enhancement: food for thought. Perspect. Psychol. Sci. 3, 102-116. doi: 10.1111/j.1745-6916.2008.00068.x

Taylor, S. E., and Brown, J. D. (1988). Illusion and well-being: a social psychological perspective on mental health. Psychol. Bull. 103, 193-210. doi: 10.1037/00332909.103.2.193

Wu, L., Gu, R., Cai, H., and Zhang, J. (2016). Electrophysiological evidence for executive control and efficient categorization involved in implicit selfevaluation. Soc. Neurosci. 11, 153-163. doi: 10.1080/17470919.2015.1044673

Conflict of Interest Statement: The authors declare that the research was conducted in the absence of any commercial or financial relationships that could be construed as a potential conflict of interest.

Copyright (C) 2019 Lou, Cai, Liu and Li. This is an open-access article distributed under the terms of the Creative Commons Attribution License (CC BY). The use, distribution or reproduction in other forums is permitted, provided the origina author(s) and the copyright owner(s) are credited and that the original publication in this journal is cited, in accordance with accepted academic practice. No use, distribution or reproduction is permitted which does not comply with these terms. 